\title{
Impact and relationship of anterior commissure and time-dose factor on the local control of T1N0 glottic cancer treated by $6 \mathrm{MV}$ photons
}

\author{
Chi-Chung Tong ${ }^{*}$, Kwok-Hung Au, Roger KC Ngan, Sin-Ming Chow, Foon-Yiu Cheung, Yiu-Tung Fu, Joseph SK Au \\ and Stephen CK Law
}

\begin{abstract}
Background: To evaluate prognostic factors that may influence local control (LC) of T1NO glottic cancer treated by primary radiotherapy (RT) with $6 \mathrm{MV}$ photons.

Methods: We retrospectively reviewed the medical records of 433 consecutive patients with T1N0 glottic cancer treated between 1983 and 2005 by RT in our institution. All patients were treated with 6 MV photons. One hundred and seventy seven (41\%) patients received 52.5 Gy in 23 fractions with 2.5 Gy/fraction, and 256 (59\%) patients received 66 Gy in 33 fractions with 2 Gy/fraction.

Results: The median follow-up time was 10.5 years. The 10-year LC rates were $91 \%$ and $87 \%$ for T1a and T1b respectively. Multivariate analysis showed LC rate was adversely affected by poorly differentiated histology (Hazard Ratio [HR]: 7.5, $p=0.035$ ); involvement of anterior commissure (HR: 2.34, $p=0.011$ ); fraction size of 2.0 Gy (HR: 2.17, $p=0.035)$ and tumor biologically effective dose (BED) $<65 \mathrm{~Gy}_{15}$ (HR: 3.38, $p=0.017$ ).

Conclusions: The negative impact of anterior commissure involvement could be overcome by delivering a higher tumor BED through using fraction size of $>2.0 \mathrm{~Gy}$. We recommend that fraction size > $2.0 \mathrm{~Gy}$ should be utilized, for radiation schedules with five daily fractions each week.
\end{abstract}

Keywords: T1N0 glottic cancer, radiotherapy, 6 MV, anterior commissure, Biologically effective dose

\section{Background}

Laryngeal cancer is the third most common head and neck $(\mathrm{H} \& \mathrm{~N})$ cancer in Hong Kong. The age-standardized incidence rate was 2.3 per 100,000 [1] and is comparable to those of other developed countries like USA, the Netherlands and Japan. In Hong Kong, around 95\% of early glottic cancer (GC) patients were treated by primary radiotherapy (RT) alone [2].

There is extensive published data regarding management of early GC treated by RT with Cobalt- 60 or $2-4$ megavoltage (MV) photons beam, with local control (LC) rates ranging from approximately $85-94 \%$ in T1N0 disease [3-5]. The reported treatment outcome of early GC by primary irradiation with $6 \mathrm{MV}$ photons is limited and conflicting. Some authors reported comparable

\footnotetext{
* Correspondence: chichungtong@hkcr.org
Department of Clinical Oncology, Queen Elizabeth Hospital, 30 Gascoigne

* Correspondence: chichungtong@hkcr.org Road, Kowloon, Hong Kong
}

(c) 2011 Tong et al; licensee BioMed Central Ltd. This is an Open Access article distributed under the terms of the Creative Commons Attribution License (http://creativecommons.org/licenses/by/2.0), which permits unrestricted use, distribution, and reproduction in any medium, provided the original work is properly cited.

\section{Methods}

Patient characteristics

In mid 2010, we conducted a retrospective analysis of laryngeal cancer patients referred to our center for radical treatment over a 26 year period between January 1983 to December 2005. A total of 1256 consecutive patients were identified. This retrospective study was approved by our Institutional Review Board and Ethics committee. According to the Hong Kong Cancer Registry, about a quarter of all laryngeal cancer cases diagnosed in Hong Kong over that period were treated in our institution. Out of the 1256 patients, there were 433 previously untreated patients with T1N0 GC. 


\section{Staging}

All patients had full physical examination, routine blood counts, renal and liver function tests, chest $\mathrm{x}$ ray, endoscopic examination and biopsy for histology diagnosis. Computed tomography (CT) scan of larynx and neck was performed in 412 (95\%) patients. Patients were restaged according to UICC TNM 2002 classification [10]. Table 1 summarized the various patient, tumor and treatment parameters.

\section{Radiotherapy Treatment}

All patients were treated exclusively with 6-MV photons from linear accelerator (LA). They were treated in a supine position, immobilized with a customized cobex $H \& N$ cast. All patients received a continuous course of RT with once-daily fractionation, 5 fractions per week. All fields were equally weighted and treated in each fraction.

\section{Field size and set up}

All patients were treated with parallel-opposed fields, to cover the glottic larynx with 1-2 cm margins. The field size was obtained by multiplying the field length by the field width. It ranged from 22-38.5 $\mathrm{cm}^{2}$ (median: $27.5 \mathrm{~cm}^{2}$ ). Typically, the superior border was put at around the top of the thyroid cartilage, the inferior border at around the bottom of the cricoid cartilage; the anterior border extended beyond the skin surface and the posterior border placed at the anterior edge of vertebral body of the cervical vertebrae. Elective nodal irradiation was not given. Optimized wedge filters were used to improve the dose homogeneity. $0.5 \mathrm{~cm}$ thickness wax up bolus was used for diseases involving or close to the anterior commissure (AC). From February 1990 , doses were prescribed to the $100 \%$ isodose line on a 2-dimensional plan derived from the plane of the patient contour at the level of the isocenter.

\section{Dose and fractionation}

RT dose was prescribed at the midline along the central axis or recalculated at the ICRU reference point. Between the period of 1983-1988 and 1996-2005, patients were treated with a fraction size of 2.0 Gy whereas during 1989-1995, a fraction size of 2.5 Gy was utilized because of constraints in LA machine in our hospital.

We opted to compute the tumor biologically effective dose (BED) by using the standard linear quadratic formula (LQ) with time factors corrected: [11]

$$
\text { Tumor BED }=n d(1+d /[\alpha / \beta])-\log _{\mathrm{e}} 2(T-T \mathrm{k}) / \alpha T \mathrm{p}
$$

where $n$ fractions of $d$ Gy are given in an overall time of $T$ days and kick off time ( $T \mathrm{k}$ ) for tumor repopulation.
Table 1 Patient, tumor and treatment parameters

\begin{tabular}{|c|c|}
\hline Parameters & Patients no (\%) \\
\hline \multicolumn{2}{|l|}{ Sex } \\
\hline Male & 413 (95.3\%) \\
\hline Female & $20(4.6 \%)$ \\
\hline \multicolumn{2}{|l|}{ T stage } \\
\hline T1a & $324(74.8 \%)$ \\
\hline $\mathrm{T} 1 \mathrm{~b}$ & 109 (25.1\%) \\
\hline \multicolumn{2}{|l|}{ Grade } \\
\hline Well differentiated & $154(35.5 \%)$ \\
\hline Mod differentiated & $273(63.0 \%)$ \\
\hline Poorly differentiated & $6(1.3 \%)$ \\
\hline \multicolumn{2}{|l|}{ AC involvement } \\
\hline Yes & 197 (45.4\%) \\
\hline No & $236(54.1 \%)$ \\
\hline \multicolumn{2}{|l|}{ Hemoglobin level } \\
\hline$\leq 13 \mathrm{~g} / \mathrm{dL}$ & $45(10.4 \%)$ \\
\hline$>13 \mathrm{~g} / \mathrm{dL}$ & $388(89.6 \%)$ \\
\hline \multicolumn{2}{|l|}{ Field size (cm2) } \\
\hline$<30.5$ & 215 \\
\hline $30.5-35.5$ & 165 \\
\hline$\geq 35.5$ & 53 \\
\hline \multicolumn{2}{|l|}{ A. Dose fraction size } \\
\hline $2.5 \mathrm{~Gy}$ & $177(40.8)$ \\
\hline \multicolumn{2}{|l|}{ Total dose (Gy) } \\
\hline 55 & $30(6.9)$ \\
\hline 57.5 & $134(30.9)$ \\
\hline 60 & $13(3.0)$ \\
\hline \multicolumn{2}{|l|}{ Tx duration (days) } \\
\hline$\leq 30$ & $25(5.7)$ \\
\hline $31-33$ & $141(32.5)$ \\
\hline$\geq 34$ & $11(2.5)$ \\
\hline \multicolumn{2}{|l|}{$\mathrm{BEDcGy}_{15}$ (cGy) } \\
\hline Median & 6520 \\
\hline range & $6058-6820$ \\
\hline \multicolumn{2}{|l|}{ B. Dose fraction size } \\
\hline $2.0 \mathrm{~Gy}$ & $256(59.1)$ \\
\hline \multicolumn{2}{|l|}{ Total dose (Gy) } \\
\hline 64 & $52(12.0)$ \\
\hline 66 & $202(46.6)$ \\
\hline 68 & $2(0.46)$ \\
\hline \multicolumn{2}{|l|}{ Tx duration (days) } \\
\hline$\leq 45$ & $48(11.0)$ \\
\hline $46-50$ & $203(46.8)$ \\
\hline$\geq 51$ & $5(1.5)$ \\
\hline \multicolumn{2}{|l|}{ BEDcGy $_{15}$ (cGy) } \\
\hline Median & 6340 \\
\hline range & $6040-6700$ \\
\hline
\end{tabular}

Abbreviations: $\mathrm{AC}=$ Anterior Commissure, $\mathrm{Tx}$ : treatment, BEDcGy $_{15}$ : Tumor biologically effective dose 
We assume $\alpha / \beta=15$ for laryngeal cancer [12], $T \mathrm{k}=28$ for tumor[13], $T \mathrm{p}=$ average cell number doubling time during continuing radiation, 3 days for tumor[14]. Alpha $(\alpha)=0.35 \mathrm{~Gy}^{-1}[14]$ [coefficient of non-repairable injury, log cell kill (exponentially-based logs) per gray of dose].

One hundred and seventy-seven $(40.8 \%)$ were treated with a dose fraction size of $2.5 \mathrm{~Gy}$, with total dose of 55-60 Gy (median: 57.5 Gy), within a treatment duration of 30-38 days (median 31 days). The most commonly used dose-fractionation schedule was $57.5 \mathrm{~Gy}$ in 23 fractions. Tumor BEDGy ${ }_{15}$ ranged from 60.5 to $68.2 \mathrm{~Gy}_{15}$ (median $\left.=65.2 \mathrm{~Gy}_{15}\right)$.

Two hundred and fifty- six (59.1\%) patients were treated with a dose fraction size of $2.0 \mathrm{~Gy}$, with a total dose of 64-68 Gy (median: 66 Gy), within a treatment duration of 44-58 days (median: 46). The most commonly used dose-fractionation schedule was 66 Gy in 33 fractions. Tumor BEDGy 15 ranged from 60.4 to $67.0 \mathrm{~Gy}_{15}$ $\left(\right.$ median $\left.=63.4 \mathrm{~Gy}_{15}\right)$.

\section{Follow up and assessment}

All patients underwent evaluation of response to treatment by endoscopy examination at 6 to 8 weeks after completion of RT treatment. Patients were regularly seen once every two or three months during the initial 2 years and then six-monthly up to 5 years and then yearly thereafter.

\section{Complications}

Acute and chronic complications were scored according to the Common Terminology Criteria for Adverse Events version 3.0 [15].

\section{Statistical analysis}

Local and neck failure was defined as clinically/radiological detectable disease in larynx and cervical lymph node (LN) respectively. Distant metastasis (DM) was defined as clinically or radiologically detectable disease outside the larynx and cervical LN. Clinicopathologic parameters that were analyzed included age ( $<61 \mathrm{vs}$. 61-70 vs. $>71$ ), gender (male vs. female), pre-treatment hemoglobin $(\mathrm{Hb})$ level (<13.0 vs. $\geq 13.0 \mathrm{~g} / \mathrm{dl}$ ), T substage (T1a vs. T1b), tumor grading (well vs. moderate vs. poorly differentiated squamous cell carcinoma), involvement of AC (yes vs. no). Treatment parameters included dose fraction size $(2.0 \mathrm{~Gy}$ vs. $2.5 \mathrm{~Gy})$, $\mathrm{BEDGy}_{15}$ given (< $65.0 \mathrm{~Gy}_{15}$ vs. $\left.\geq 65.0 \mathrm{~Gy}_{15}\right)$, treatment field size in $\mathrm{cm}^{2}$ (< 30.5 vs. $30.5-35.5$ vs. $>35.5$ ), and treatment period (1983-1990 vs. 1991-2000 vs. 20012005).

All time-related events were measured from date of the first RT treatment. The actuarial local/neck failure rate and ultimate local/neck failure rate were calculated by the Kaplan-Meier method. Difference of the endpoints stratified by the various prognostic factors were evaluated by the Log- rank test.

Cox proportional hazard model was used for both univariate and multivariate analysis to determine the hazard ratios and significance of potential risk factors for local control (LC). All statistical tests were two-sided and performed at the 0.05 level of significance ( $p$ value). Only factors with a level of significance less than 0.05 in univariate analysis would be further analyzed in the multivariate analysis. We used SPSS, version 15.0, (SPSS Inc., Chicago, IL) for all statistical analyses.

\section{Results}

\section{Local and Neck control}

The median follow-up time was 10.5 years (range 3.3 26.6 years). The clinical course of this patient cohort is shown in figure 1 . The 5-year and 10-year LC rates for T1a group were $92 \%$ and $91 \%$ respectively whereas those for T1b group were $89 \%$ and $87 \%$ respectively (figure 2a).

Complete response (CR) was achieved in 430 (99.3\%) patients, while $3(0.7 \%)$ patients had residual disease/disease progression at vocal cord(s) at 8 weeks after completion of RT. Thirty-six (8.3\%) among the 430 patients who achieved CR had their first relapse observed at a median interval of 15 months after completion of RT treatment. All first relapses occurred in the laryngeal

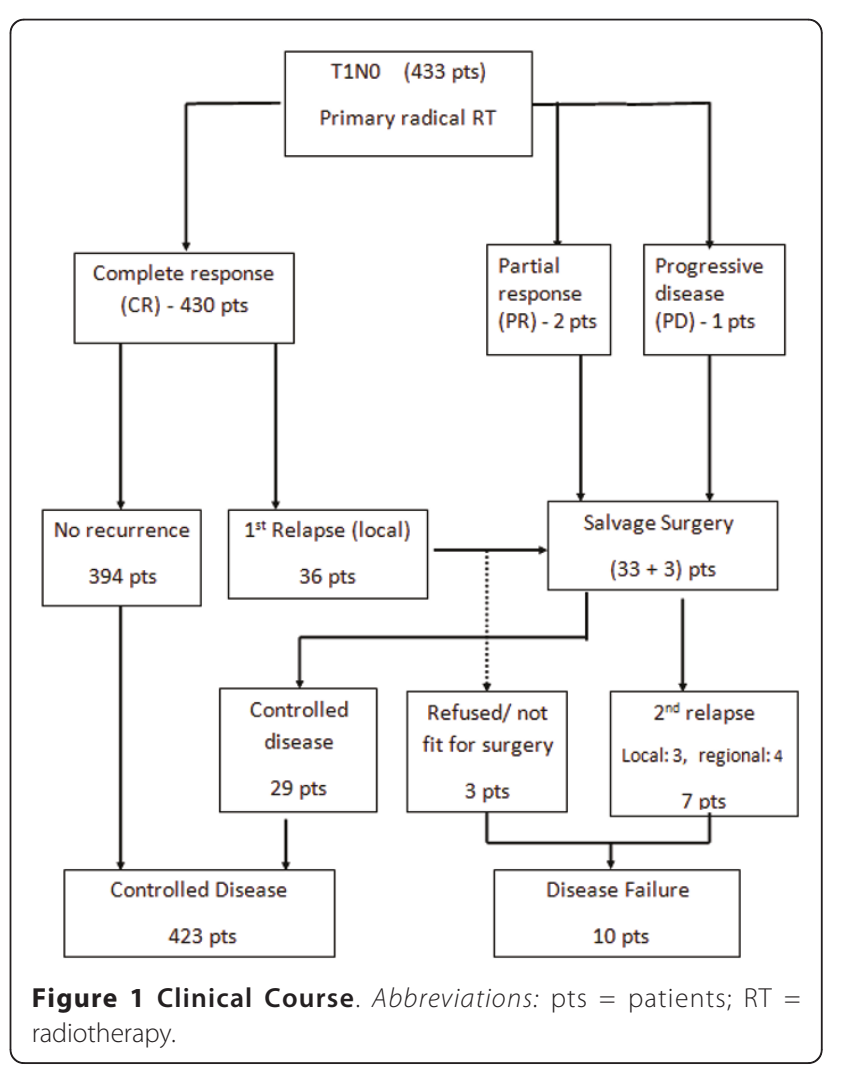




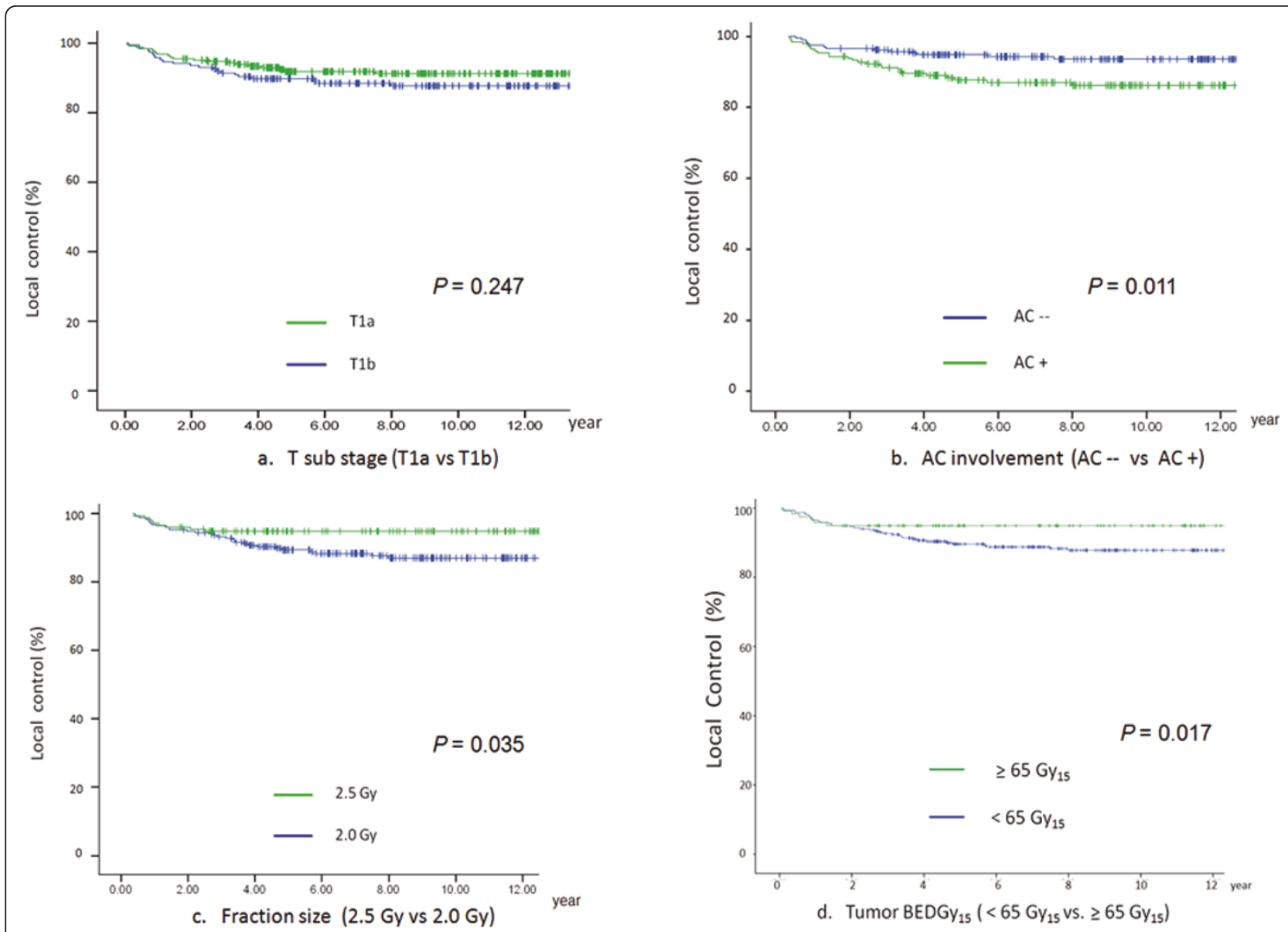

Figure 2 Local control rate according to $\mathrm{T}$ sub-stage; AC involvement; Fraction size; tumor BEDGy ${ }_{15}$. a. T sub stage (T1a vs T1b). b. AC involvement (AC - vs AC +). c. fraction size (2.5 Gy vs $2.0 \mathrm{~Gy}$ ). d. Tumor BEDGy ${ }_{15}\left(<65 \mathrm{~Gy}_{15}\right.$ vs $\geqq 65 \mathrm{~Gy}_{15}$ ). Abbreviations: AC: anterior commissure; $A C-$ : absence of $A C$ involvement; $A C+$ : presence of $A C$ involvement; $B E D$ : biologically effective dose.

glottis and none of them occurred in neck LNs or distant sites.

\section{Salvage surgery after recurrence/residual disease}

Of the 39 patients who developed local recurrence or persistent disease, 36 were salvaged by total laryngectomy. Three patients refused or were not considered medically fit for salvage treatment. Seven patients developed second relapse or progression as regional or distant metastasis despite total laryngectomy, resulting in overall ultimate disease failure in 10 patients. This resulted in an ultimate 10 year LC of $97 \%$. Larynx preservation was achieved in 394 (91\%) patients.

\section{Complications}

RT was well tolerated by all patients. No patient had grade III or IV toxicity that necessitated treatment interruption $>3$ days, nasogastric tube feeding, intravenous fluid supplement or tracheostomy. There is no clinical or radiological chondroradionecrosis that warranted laryngectomy.

\section{Factors affecting Local Control}

On multivariate analysis, LC was adversely affected by poorly differentiated histology (Hazard Ratio [HR]: 7.5, $p=0.035$ ); involvement of AC (HR: 2.34, $p=0.011$ ); fraction dose size of $2.0 \mathrm{~Gy}$ (HR: 2.17, $p=0.035$ ) and tumor BEDGy $15<65 \mathrm{~Gy}_{15}$ (HR: $3.38, p=0.017$ ) [table 2].

Figure $2 \mathrm{~b}$ depicts $\mathrm{LC}$ rate according to presence of $\mathrm{AC}$ involvement. There was a significant difference in $\mathrm{LC}$ between those with presence of $\mathrm{AC}$ involvement and without AC involvement ( $86 \%$ vs. $95 \%$ at 5 years, $85 \%$ vs. $94 \%$ at 10 years $(p=0.011)$. Figure $2 \mathrm{c}$ depicts LC rate according to fraction size. There was a significant difference between the 2.0 Gy group and the 2.5 Gy group ( $89 \%$ vs. $95 \%$ at 5 years; $87 \%$ vs. $95 \%$ at 10 year, $p$ $=0.035$ ). Figure $2 \mathrm{~d}$ depicts $\mathrm{LC}$ rate according to tumor BEDGy $_{15}$. There was a significant difference between the group with tumor BED $<65 \mathrm{~Gy}_{15}$ vs. the group with tumor BED $\geq 65 \mathrm{~Gy}_{15}$ (90\% vs. $96 \%$ at 5 years; $88 \%$ vs. $96 \%$ at 10 years, $p=0.017$ ). 
Table 2 Univariate and multivariate analysis of factors affecting local control

\begin{tabular}{|c|c|c|c|c|}
\hline \multirow[t]{2}{*}{ Parameters } & \multirow[t]{2}{*}{$\begin{array}{l}\text { Events/ } \\
\text { patients }\end{array}$} & \multirow{2}{*}{$\begin{array}{c}\begin{array}{c}\text { Uni-variate } \\
\text { analysis }\end{array} \\
P \text { value }\end{array}$} & \multicolumn{2}{|c|}{$\begin{array}{c}\text { Multivariate } \\
\text { analysis }\end{array}$} \\
\hline & & & $\begin{array}{c}\text { HR }(95 \% \\
\text { Cl) }\end{array}$ & $\begin{array}{c}P \\
\text { value }\end{array}$ \\
\hline \multicolumn{5}{|l|}{ Age } \\
\hline$<61$ & $18 / 142$ & & & \\
\hline $61-70$ & $15 / 153$ & 0.302 & - & - \\
\hline$>70$ & 9/138 & & & \\
\hline \multicolumn{5}{|l|}{ Sex } \\
\hline Male & $41 / 413$ & 0.445 & - & - \\
\hline Female & $1 / 20$ & & & \\
\hline \multicolumn{5}{|l|}{ Sub-stage } \\
\hline $\mathrm{T} 1 \mathrm{~A}$ & $28 / 324$ & 0.24 & - & - \\
\hline $\mathrm{T} 1 \mathrm{~B}$ & $14 / 109$ & & & \\
\hline \multicolumn{5}{|l|}{ Grade } \\
\hline Well diff & $9 / 154$ & & 1 & \\
\hline Mod diff & $29 / 273$ & $0.0001^{*}$ & $\begin{array}{l}1.91(1.2- \\
3.85)\end{array}$ & $0.035^{\star}$ \\
\hline Poorly diff & $4 / 6$ & & $\begin{array}{l}7.5(3.42- \\
15.24)\end{array}$ & \\
\hline \multicolumn{5}{|l|}{$\mathrm{Hb}$} \\
\hline$<13.0$ & $6 / 45$ & 0.367 & - & - \\
\hline$\geq 13.0$ & $36 / 388$ & & & \\
\hline \multicolumn{5}{|l|}{$A C$} \\
\hline No & $14 / 236$ & $0.004^{*}$ & 1 & $0.011^{*}$ \\
\hline Yes & 28/197 & & $\begin{array}{c}2.34(1.21- \\
4.52)\end{array}$ & \\
\hline \multicolumn{5}{|l|}{$\begin{array}{l}\text { Field size } \\
\left(\mathrm{cm}^{2}\right)\end{array}$} \\
\hline$<30.5$ & $35 / 215$ & & & \\
\hline $30.5-35.5$ & $7 / 165$ & 0.534 & - & - \\
\hline$>35.5$ & $0 / 53$ & & & \\
\hline \multicolumn{5}{|l|}{ Dose size } \\
\hline 2.0 Gy & $32 / 256$ & $0.021^{*}$ & $\begin{array}{c}2.17(1.28- \\
4.18)\end{array}$ & $0.035^{*}$ \\
\hline $2.5 \mathrm{~Gy}$ & 10/177 & & 1 & \\
\hline \multicolumn{5}{|l|}{ Tumor BED } \\
\hline$<65\left(G y_{15}\right)$ & 29/239 & $0.025^{*}$ & $\begin{array}{c}3.38(1.29- \\
7.83)\end{array}$ & $0.017^{*}$ \\
\hline$\geq 65\left(G y_{15}\right)$ & 13/194 & & 1 & \\
\hline \multicolumn{5}{|l|}{ Tx period } \\
\hline 1983-1990 & $10 / 115$ & & & \\
\hline $1991-2000$ & $25 / 224$ & 0.643 & - & - \\
\hline $2001-2005$ & $7 / 94$ & & & \\
\hline
\end{tabular}

Abbreviations: $\mathrm{HR}=$ Hazard ratio; $\mathrm{Cl}=$ confidence interval; $\mathrm{Gy}=\mathrm{Gray}$; diff $=$ differentiated $; \mathrm{AC}=$ anterior commissure; $\mathrm{BED}=$ Biologically Effective Dose;

* $=$ statistically significant

We further categorized patients into 4 groups (A1-A4) according to involvement of $\mathrm{AC}$ and fraction size (category- A) or another 4 groups (B1-B4) according to involvement of $\mathrm{AC}$ and tumor BED (category-B), i.e.
Table 3 Category- A: grouping according to AC involvement and fraction size

\begin{tabular}{ccc}
\hline & AC- & AC+ \\
\hline 2.5 Gy/fraction & 94 (A1) & 83 (A3) \\
\hline 2.0 Gy/fraction & $142(\mathrm{A2})$ & 114 (A4) \\
\hline
\end{tabular}

(A1) no AC involvement with fraction size of $2.5 \mathrm{~Gy}$, (A2) no AC involvement with fraction size of $2.0 \mathrm{~Gy}$, (A3) presence of $A C$ involvement with fraction size of $2.5 \mathrm{~Gy}$, (A4) presence of AC involvement with fraction size of 2.0 Gy [table 3]; (B1) no AC involvement and BED $\mathrm{Gy}_{15} \geq 65 \mathrm{~Gy}_{15}$, (B2) no AC involvement and BED $\mathrm{Gy}_{15}<65 \mathrm{~Gy}_{15}$, (B3) presence of AC involvement and BED $\mathrm{Gy}_{15} \geqq 65 \mathrm{~Gy}_{15}$, (B4) presence of AC involvement and BED Gy15 $<65 \mathrm{~Gy}_{15}$ [table 4].

There was a statistically significant difference in LC rates among 4 groups in category-A: $96 \%$ vs. $93 \%$ vs. $91 \%$ vs. $82 \%$ respectively at 5 years; $96 \%$ vs. $92 \%$ vs. $91 \%$ vs.79\% respectively at 10 year $(p=0.002)$ [figure 3a]. Again, similar statistically significant difference in LC rates was also observed among 4 groups in category-B: $96 \%$ vs. $92 \%$ vs. $89 \%$ vs. $82 \%$ at 5 years; $96 \%$ vs. $92 \%$ vs. $89 \%$ vs. $80 \%$ respectively at 10 year $p=0.003$ [figure 3b].

\section{Discussion}

In western countries, both definitive RT and conservative surgery (endoscopic laser surgery/open organ preserving surgery) are accepted standard treatment modalities for stage one GC [16,17]. A survey conducted in eleven regions/countries in Asia revealed that in regions following the 'British school' like Hong Kong and Singapore, RT alone has remained the primary treatment modality for early laryngeal cancers [2]. As laser surgery has become more popular since Stener's landmark report [18], it is expected that it will be increasingly employed in local institutions.

Focusing on primary irradiation, there is extensive literature regarding the efficacy and prognostic factors for RT in early GC [3-5,19-23]. All data except one series [24] was retrospective series. Broadly, prognostic factors can be divided into patient/tumor- as well as treatmentrelated factors. Apart from stage, other patient or tumor prognostic factors have been reported, including tumor bulk $[4,19,25]$, bilaterality $[4,5]$, AC involvement (see below), tumor grade $[3,26]$ and hemoglobin level

Table 4 Category- B: grouping according to AC involvement and BED

\begin{tabular}{ccc}
\hline & AC- & AC+ \\
\hline $\mathrm{BED} \geq 65 \mathrm{~Gy}_{15}$ & $94(\mathrm{~B} 1)$ & $100(\mathrm{~B} 3)$ \\
\hline $\mathrm{BED}<65 \mathrm{~Gy}_{15}$ & $142(\mathrm{~B} 2)$ & $97(\mathrm{~B} 4)$ \\
\hline
\end{tabular}

Abbreviations: $\mathrm{AC}=$ anterior commissure; $\mathrm{BED}=$ Biologically Effective Dose 


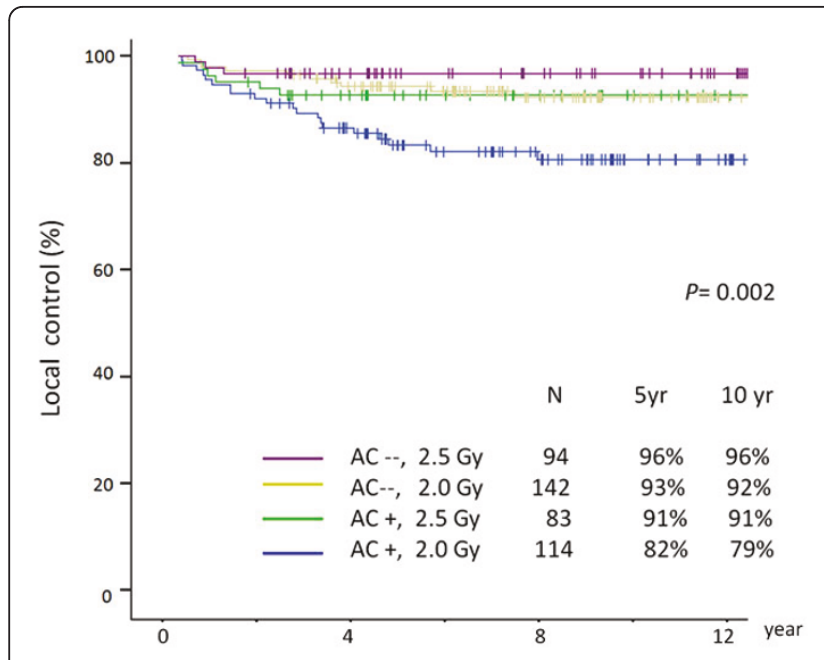

A

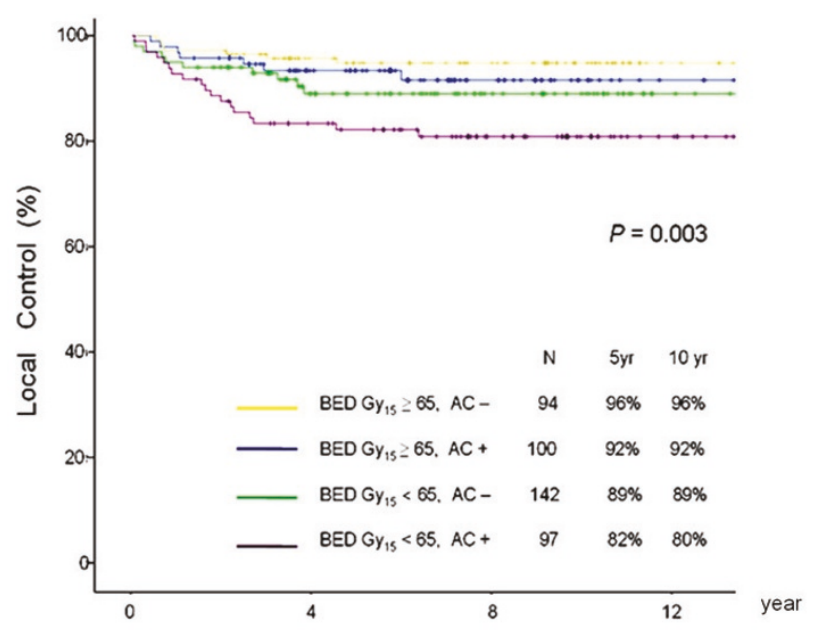

B

Figure 3 Local control rate according fraction size, tumor BED 15, AC involvement. a. fraction size, together with AC involvement. b. tumor BED G15, together with AC involvement. Abbreviations: AC: anterior commissure tumor BED $\mathrm{Gy}_{15}$ : tumor biologically effective dose N: patients numbers $A C-$ : absence of $A C$ involvement $A C+$ : presence of $A C$ involvement

$[5,26,27]$. Radiation treatment- related factors included dose fraction size, total dose, overall treatment time (OTT) [see below].

The majority of these published data were derived from patients treated by Cobalt-60 machine or LA generating 2-4 MV photons [3-5,21,26]. In many RT centers, these therapy units have been decommissioned. With a general shift from the use of Cobalt-60 to LA treatment units, it is anticipated that $6 \mathrm{MV}$ photon beams generated by LA will become the prevailing workhorse for treatment in clinical practice [28]. Table 5 showed published results for T1N0 GC treated with $6 \mathrm{MV}$ photons in the recent two decades.

The impact of AC involvement on the RT treatment outcome of early GC is still controversial. The so called $\mathrm{AC}$ or Broyle's tendon is the insertion of vocalis tendon into thyroid cartilage in the area of AC. This is considered as a weak point for tumor spread because in this area, there is no thyroid cartilage perichondrium to resist tumor spread. Although some data suggested that $\mathrm{AC}$ involvement portended a worse prognosis, it has not been included in the staging system.

In the recent two decades, many authors identified AC involvement as one of the independent poor prognostic factors in LC for T1N0 GC treated by primary RT $[4,21,29]$. In a recent report by Smee et al. [30], it was found that $\mathrm{AC}$ involvement was one of the independent poor prognostic factors for $\mathrm{LC}$ as well as cause specific survival. One explanation is related to the possibility of 'understaging' without CT scan staging, as patients might have a larger tumor burden anteriorly, and in some cases unrecognized subglottic extension [31]. In

Table 5 Reports in literature on results of T1NO glottic cancer treated with 6 MV photons

\begin{tabular}{|c|c|c|c|c|}
\hline Author year [ref] & Patients no & Total Dose (Gy) & Dose size (Gy) & Local Control (5 year)\% \\
\hline Akine et al. 1991 [7] & 151 & $62.5-67.5$ & $2.0-2.4$ & 89 \\
\hline Fein et al. 1996 [27] & 43 & 66 & 2 & 95 \\
\hline Foote et al. 1996 [6] & 27 & 63 & 2.25 & 100 \\
\hline Lee et al. 2001 [28] & 86 & 66 & 2 & $\begin{array}{l}\text { T1a: } 82 \\
\text { T1b: } 76\end{array}$ \\
\hline Gowda et al. 2003 [36] & 100 & $50-52.5$ & $3.12-3.28$ & $\begin{array}{l}\text { T1a: } 93 \\
\text { T1b: } 89\end{array}$ \\
\hline Franchin et al. 2003 [20] & 323 & $63-65.2$ & 2.25 & T1: 90 \\
\hline Sjögren et al. 2009 [37] & 59 & 60 & $2.0-2.8$ & $\begin{array}{l}\text { T1a: } 87 \\
\text { T1b: } 85\end{array}$ \\
\hline current study & 433 & $57.5-66$ & $2.0-2.5$ & $\begin{array}{l}\text { T1a: } 92 \\
\text { T1b: } 89\end{array}$ \\
\hline
\end{tabular}


our patient cohort, since $95 \%$ of patients had evaluation by CT scan, the issue of under-staging should be minimal.

Another probable reason is the theoretical risk of under-dosage at the air-tissue interface with the depthdose characteristics of $6 \mathrm{MV}$ photons compared with those of Cobalt- 60 beam. This is related to inadequate tissue present at the area of $\mathrm{AC}$ where the neck is thin, as well as lack of electronic equilibrium at the air-tissue interface which might be more pronounced with highenergy photons treated with small field size $[32,33]$. Hence, poorer coverage of the prescribed dose to the tumor may occur in early glottic tumors with AC involvement, particularly when treated with $6 \mathrm{MV}$ photons. Sombeck et al. [34] performed a dosimetric evaluation comparing 6MV photons with Cobalt-60 beam. They revealed that there was no significant difference in the dose received at any point along the vocal cords. On the other hand, a recent study by Spirydovich [35] demonstrated a significant under- dosage occurring at the airtissue interface of larynx treated by $6 \mathrm{MV}$ photons. The authors performed Monte Carlo dose calculation to CTbased mathematical neck. They identified that at least $5 \%$ of a hypothetical tumor of $3.5 \mathrm{~cm}^{3}$ received less than $86 \%$ of the maximum tumor dose in neck that contains air cavities in comparison to $91 \%$ of the maximum tumor dose in the homogeneous neck.

However, some other major reports did not reveal the impact of AC on LC of early glottic cancer $[3,5,36,37]$.

With regard to the impact of dose fraction size for early glottic disease, there is little controversy that inferior LC is associated with fraction size $<2.0$ Gy when patients are treated once daily, 5 days per week $[38,39]$.

Among the reports published in the literature, the common contemporary irradiation schedules for T1N0 GC included: 66 Gy in 33 fractions in 6.5 weeks, 63 Gy in 28 fractions in 5.5 weeks, and 60 Gy in 25 fractions in 5 weeks $[17,40]$. In fact, a prospective randomized study from Yamazaki et al. [24] demonstrated a statistically superior 5 -year LC rate of $92 \%$ for patients treated with fraction size of 2.25 Gy compared with $77 \%$ for those treated with $2.0 \mathrm{~Gy}$.

Besides, many reports have shown that prolonging OTT in T1N0 GC has an adverse impact on LC and dose compensation is needed to maintain the tumor control probability. Indeed, several authors have highlighted the complex inter- relationship among the variables of total dose, fraction size and OTT [41,42].

Fowler [43] commented that according to radiobiological principles, even if there would be a positive effect of increasing total dose or fraction size on LC, and a strong negative effect of treatment prolongation, these effects become minimal where the LC was already at a very high level, because of the plateau of the slope of the sigmoid- shaped dose-response curve above 70 or $80 \%$. This theoretical postulation has also been verified by observations reported. Fein et al.[27] and Le et al. [21] did not observe a relationship between fraction size and LC. Although there was a trend for higher LC in patients treated with fraction size of $\sim 2.25$ Gy when compared to smaller fraction size, the difference did not reach statistical significance. The authors attributed the lack of difference to the low recurrence rate in $\mathrm{T} 1$ lesions, thus under- powering the studies to demonstrate a significant relationship between fraction size and LC.

The debate over these discrepancies was rebuffed after the impact of shortening of OTT in LC of H\&N cancers was confirmed in randomized trials with accelerated schedules. Both the Danish Head and Neck Cancer Study Group study (DAHANCA 6 \& 7) [44] and the International Atomic Energy Agency (IAEA- ACC) trial [45] delivered six fractions per week but keeping same total dose, enabled a treatment of $66 \mathrm{~Gy}$ in 33 fractions to be given in 8 days less than the conventional schedule. They revealed a $10-12 \%$ improvement in LC of $H \& N$ cancers (especially for early laryngeal cancer subset) upon shortened OTT. It appeared that by shortening the OTT, treatment outcome is improved as accelerated repopulation of tumor clonogens would be reduced. But these accelerated schedules are also shown to have more acute radiation toxicity in terms of severe skin reactions, confluent mucositis necessitating tube feeding.

In evaluating the efficacy of various fractionation schedules, we opted to test the impact of tumor BEDGy ${ }_{15}$ which incorporates the components of fraction size, OTT and total dose. Our analysis shows that tumor BED $\geq 65 \mathrm{~Gy}_{15}$ is associated with better LC. Table 6 illustrated the common radiation schedules in which fraction size is $>2.0 \mathrm{~Gy}$, the resulting tumor $\mathrm{BEDGy}_{15}$ would be $>65 \mathrm{~Gy}_{15}$ but the BEDs for both early mucosa and late normal tissues are well below the corresponding dose constraints for complications [aim at 59-63 $\mathrm{Gy}_{10}$ for acute mucosa; $<117 \mathrm{~Gy}_{3}$ for late normal tissue respectively] [46].

Since the treatment field size for T1N0 GC is small, it permits slight hypofractionated schedule without causing excessive acute radiation toxicity. Shortened OTT overcomes the accelerated repopulation of tumor clonogens.

This also supports the current contemporary practice of fraction dose size $>2.0$ Gy (i.e. 2.25 Gy) for treatment of T1N0 GC by other centers $[3,6,20,21,24,37]$

To the best of our knowledge, our report is the largest study on RT outcomes in T1N0 GC primarily treated with $6 \mathrm{MV}$ photons. As the treatment of choice for early GC in our institution or Hong Kong at large has 


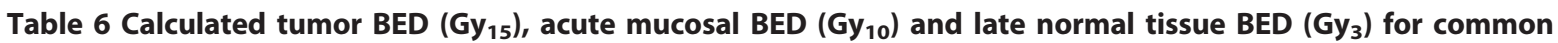
radiation schedules

\begin{tabular}{|c|c|c|c|c|c|c|c|}
\hline $\begin{array}{l}\text { Dose } \\
\text { size } \\
\text { (Gy) }\end{array}$ & $\begin{array}{l}\text { Fraction } \\
\text { number }\end{array}$ & $\begin{array}{l}\text { Total } \\
\text { dose } \\
\text { (Gy) }\end{array}$ & $\begin{array}{l}\text { Overall treatment } \\
\text { time (OTT) in days }\end{array}$ & $\begin{array}{c}\text { Tumor } \\
\text { BED } \\
\left(\mathrm{Gy}_{15}\right)\end{array}$ & $\begin{array}{l}\text { Acute Mucosal BED }\left(\mathrm{Gy}_{10}\right) \\
\quad\left(\text { aim } 59-63 \mathrm{~Gy}_{10}\right)[46]\end{array}$ & $\begin{array}{l}\text { Late normal BED }\left(\mathrm{Gy}_{3}\right) \\
\quad\left(\text { aim }<117 \mathrm{~Gy}_{3}\right)[46]\end{array}$ & references \\
\hline 2.0 & 33 & 66 & 45 & 64.60 & 49.1 & 110 & $\begin{array}{l}{[22,25,27] \&} \\
\text { current study }\end{array}$ \\
\hline 2.25 & 28 & 63 & 38 & 66.45 & 52.62 & 110.2 & {$[3,5,20,24,37]$} \\
\hline 2.5 & 23 & 57.5 & 31 & 65.28 & 52.87 & 105.4 & current study \\
\hline
\end{tabular}

$\mathrm{BED}=$ biologically effective dose

$=$ total dose $(1+$ fraction size $/[\alpha / \beta])-\log _{\mathrm{e}} 2(O T T-T \mathrm{k}) / \alpha T \mathrm{p}[14]$

Assume: $1 . \alpha / \beta=15$ for laryngeal cancer [12]

2. $T \mathrm{k}$ : kick off time $(T \mathrm{k})$ for tumor repopulation $=28$ days [13]

3. $T p=$ average cell number doubling time during continuing radiation, 3 days for tumor [14]

4. Alpha $(\alpha)=$ [coefficient of non-repairable injury, log cell kill (exponentially-based logs) per gray of dose]

$\left.=0.35 \mathrm{~Gy}^{-1}(14)\right]$

been and in the near future will still be RT alone [2], this represents a relatively unselected cohort of patients. While this study spans a considerable period of time, the clinical evaluation and treatment techniques have been consistent over the years, thus allowing a valid analysis to be performed. Our results demonstrate that the LC rate with primary RT with $6 \mathrm{MV}$ photons is comparable and agrees with other reports of "unremarkable" treatment outcome difference when comparing Cobalt-60 beam and $6 \mathrm{MV}$ photons [3,5-7,27].

\section{However, we observe that $A C$ involvement is associated with a poor LC rate}

We suspect that the issue of 'cold spot' is more apparent at the AC region, especially when treated with $6 \mathrm{MV}$ photons. Certainly, further dosimetric evaluation is needed to validate this suspicion. While involvement of $\mathrm{AC}$ is an adverse prognostic factor, we have shown that its negative impact can be overcome by delivering a higher tumor BED ( $\left.\geqq 65 \mathrm{~Gy}_{15}\right)$. In order to achieve this tumor BED level in conventional schedule of five daily fractionation each week, we recommend that fraction size $>2.0$ Gy should be utilized. In fact, modest hypofractionation is safe and effective for T1N0 GC in terms of both LC and morbidity. Having a shorter OTT is more convenient for patients and is also more costeffective for RT facility implication.

Nevertheless, the results need to be interpreted with caution, because the current report was a retrospective, single institution study and therefore subjected to biases. For example, we did not have volume measurements on tumor, which has been shown in other reports as one of the important prognostic factors in LC $[4,19,25]$. In fact, AC involvement may reflect "tumor bulk" and thus may represent a surrogate marker for tumor volume. We suggest the degree of AC involvement should be further defined to better evaluate and confirm its significance in outcome prognostication. We also agree with some authors that the degree of AC involvement should be incorporated into the new UICC staging system for better comparison of results among various studies [47]. Besides, modification of the RT treatment technique like adding anterior field/anterior oblique field can be considered to combat under-dosage at AC [3,20].

\section{Conclusions}

Our data concur with other published result about the efficacy of RT with $6 \mathrm{MV}$ photons for T1N0 GC. While involvement of $\mathrm{AC}$ is associated with poor LC rate, its negative impact could be overcome by delivering a higher tumor BED through using fraction size of $>2.0$ Gy. We recommend that fraction size $>2.0$ Gy should be utilized, for radiation schedules with five daily fractions each week.

\section{Authors' contributions}

CCT participated in the study's design and coordination, performed acquisition of data and drafted the manuscript. KHA and FYC participated in data analysis and revised the manuscript. RKCN and SMC participated in study's design and revised the manuscript. JSKA, YTF and SCKL revised manuscript critically for important intellectual content. All authors read and approved the final manuscript.

\section{Competing interests}

The authors declare that they have no competing interests.

Received: 13 February 2011 Accepted: 21 May 2011

Published: 21 May 2011

\section{References}

1. Hospital Authority: Hong Kong Cancer Registry web site.[http://www.3.ha. org.hk/cancereg/e_stat.asp].

2. Wei W: Management of early carcinoma of the larynx: the Asian perspective. ENT News 2000, 9:18-19.

3. Mendenhall WM, Amdur RJ, Morris CG, et al: T1-T2N0 Squamous Cell Carcinoma of the Glottic Larynx Treated With Radiation Therapy. J Clin Oncol 2001, 19:4029-4036.

4. Cellai E, Frata P, Magrini SM, et al: Radical radiotherapy for early glottic cancer: Results in a series of 1087 patients from two Italian radiation oncology centers. I. The case of T1N0 disease. International Journal of Radiation Oncology Biology Physics 2005, 63:1378-1386. 
5. Warde $P, O$ 'Sullivan $B$, Bristow RG, et al: $T 1 / T 2$ Glottic Cancer Managed by External Beam Radiotherapy: The Influence of Pretreatment Hemoglobin on Local Control. International Journal of Radiation Oncology, Biology, Physics 1998, 41:347-353.

6. Foote RL, Grado GL, Buskirk SJ, et al: Radiation therapy for glottic cancer using 6-MV photons. Cancer 1996, 77:381-386.

7. Akine Y, Tokita N, Ogino T, et al: Radiotherapy of T1 glottic cancer with 6 MeV X rays. International Journal of Radiation Oncology Biology Physics 1991, 20:1215-1218.

8. Izuno I, Sone S, Oguchi M, et al: Treatment of early vocal cord carcinoma with 60 Co gamma rays, $8 / 10 \mathrm{MV} \mathrm{X}$-rays, or $4 \mathrm{MV} \mathrm{X}$-rays - are the results different ? Acta Oncol 1990, 29:637-639.

9. Devineni VR, King K, Perez C: Early glottic carcinoma treated with radiotherapy: impact of treatment energy on sucess rate. International Journal of Radiation Oncology Biology Physics 1992, 24:106.

10. Sobin LH, Wittekind CH: UICC TNM Classification of malignant tumours. New York:: John Wiley \& Sons; 62002.

11. Fowler JF: The linear-quadratic formula and progress in fractionated radiotherapy. British Journal of Radiology 1989, 62:679-694.

12. Robertson $A G$, Robertson $C$, Boyle $P$, et al: The effect of differing radiotherapyeutic schedules on the response of glottic carcinoma of the larynx. Eur J Cancer 1993, 29A:501-510.

13. Skladowski K, Law MG, Maciejewski B, et al: Planned and unplanned gaps in radiotherapy: The importance of gap position and gap duration. Radiotherapy and Oncology 1994, 30:109-120.

14. Fowler JF: 21 years of Biologically Effective Dose. Br J Radiol 2010, 83:554-568.

15. Trotti A, Colevas AD, Setser A, et al: CTCAE v3.0: development of a comprehensive grading system for the adverse effects of cancer treatment. Seminars in Radiation Oncology 2003, 13:176-181.

16. Pfister DG, Laurie SA, Weinstein GS, et al: American Society of Clinical Oncology Clinical Practice Guideline for the Use of Larynx-Preservation Strategies in the Treatment of Laryngeal Cancer. J Clin Oncol 2006, 24:3693-3704.

17. Kaanders JH, Hordijk GJ: Carcinoma of the larynx: the Dutch national guideline for diagnostics, treatment, supportive care and rehabilitation. Radiotherapy and Oncology 2002, 63:299-307.

18. Steiner W: Results of curative laser microsurgery of laryngeal carcinomas. American Journal of Otolaryngology 1993, 14:116-121.

19. Jing J, Zhongxing $L, L i G$, et al: Analysis of prognostic factors for T1NOMO glottic cancer treated with definitive radiotherapy alone: experience of the cancer hospital of Peking Union Medical College and the Chinese Academy Of Medical Sciences. International Journal of Radiation Oncology, Biology, Physics 2002, 54:471-478.

20. Franchin G, Minatel E, Gobitti C, et al: Radiotherapy for patients with early-stage glottic carcinoma. Cancer 2003, 98:765-772.

21. Le Q-TX, Fu KK, Kroll S, et al: Influence of fraction size, total dose, and overall time on local control of T1-T2 glottic carcinoma. International Journal of Radiation Oncology Biology Physics 1997, 39:115-126.

22. Yu E, Shenouda G, Beaudet MP, et al: Impact of radiation therapy fraction size on local control of early glottic carcinoma. International Journal of Radiation Oncology Biology Physics 1997, 37:587-591.

23. Johansen LV, Grau C, Overgaard J: Glottic carcinoma - patterns of failure and salvage treatment after curative radiotherapy in 861 consecutive patients. Radiotherapy and Oncology 2002, 63:257-267.

24. Yamazaki H, Nishiyama K, Tanaka E, et al: Radiotherapy for early glottic carcinoma (T1NOMO): Results of prospective randomized study of radiation fraction size and overall treatment time. International Journal of Radiation Oncology Biology Physics 2006, 64:77-82.

25. Reddy SP, Mohideen N, Marra S, et al: Effect of tumor bulk on local control and survival of patients with T1 glottic cancer. Radiotherapy and oncology 1998, 47:161-166.

26. Johansen LV, Grau C, Overgaard J: Laryngeal Carcinoma - multivariate analysis of prognostic factors in 1252 consecutive patients treated with primary radiotherapy. Acta Oncologica 2003, 42:771-778.

27. Fein DA, Lee WR, Hanlon AL, et al: Do overall treatment time, field size, and treatment energy influence local control of T1-T2 squamous cell carcinomas of the glottic larynx? International Journal of Radiation Oncology Biology Physics 1996, 34:823-831.
28. Lee JH, Machtay M, McKenna MG, et al: Radiotherapy with 6-megavolt photons for early glottic carcinoma: Potential impact of extension to the posterior vocal cord. American Journal of Otolaryngology 2001, 22:43-54.

29. Marshak G, Brenner B, Shvero J, et al: Prognostic factors for local control of early glottic cancer: the Rabin Medical Center retrospective study on 207 patients. International Journal of Radiation Oncology Biology Physics 1999, 43:1009-1013.

30. Smee Rl, Meagher NS, Williams JR, et al: Role of radiotherapy in early glottic carcinoma. Head \& Neck 2010, 32:850-859.

31. Sessions DG, Ogura JH, Fried MP: The anterior commissure in glottic carcinoma. Laryngoscope 1975, 85:1624-1632.

32. Epp ER, Boyer AL, Doppke KP: Underdosing of lesions resulting from lack of electronic equilibrium in upper respiratory air cavities irradiated by 10 MV X- ray beams. International Journal of Radiation Oncology Biology Physics 1977, 2:613-619.

33. Klein $\mathrm{EE}$, Chin $\mathrm{LM}$, Rice RK, et al: The influence of air cavities on interface doses for photon beams. International Journal of Radiation Oncology Biology Physics 1993, 27:419-427.

34. Sombeck MD, Kalbaugh KJ, Mendenhall WM, et al: Radiotherapy for early vocal cord cancer: A dosimetric analysis of CO-60 versus $6 \mathrm{MV}$ photons. Head \& Neck 1996, 18:167-173.

35. Spirydovich S, Papiez L, Moskvin V, et al: Evaluation of underdosage in the external photon beam radiotherapy of glottic carcinoma: Monte Carlo study. Radiotherapy and Oncology 2006, 78:159-164.

36. Gowda RV, Henk JM, Mais KL, et al: Three weeks radiotherapy for T1 glottic cancer: the Christie and Royal Marsden Hospital Experience. Radiotherapy and Oncology 2003, 68:105-111.

37. Sjögren EV, Wiggenraad RG, Le Cessie S, et al: Outcome of radiotherapy in T1 glottic carcinoma: a population-based study. European Archives of OtoRhino-Laryngology 2009, 266:735-744.

38. Kim RY, Marks ME, Salter MM: Early-stage glottic cancer: importance of dose fractionation in radiation therapy. Radiology 1992, 182:273-275.

39. Mendenhall WM, Parsons JT, Million RR, et al: T1-T2 squamous cell carcinoma of the glottic larynx treated with radiation therapy: relationship of dose-fractionation factors to local control and complications. International Journal of Radiation Oncology Biology Physics 1988, 15:1267-1273.

40. NCCN Practice Guidelines in Oncology- v.2.2010:[http://www.nccn.org].

41. Skladowski K, Tarnawski R, Maciejewski B, et al: Clinical radiobiology of glottic T1 squamous cell carcinoma. International Journal of Radiation Oncology Biology Physics 1999, 43:101-106.

42. van der Voet JC, Keus RB, Hart AA, et al: The impact of treatment time and smoking on local control and complications in T1 glottic cancer. International Journal of Radiation Oncology Biology Physics 1998, 42:247-255.

43. Fowler JF: Fractionation and glottic carcinoma. International Journal of Radiation Oncology Biology Physics 1997, 39:1-2.

44. Overgaard J, Hansen HS, Specht L, et al: Five compared with six fractions per week of conventional radiotherapy of squamous-cell carcinoma of head and neck: DAHANCA 6\&7 randomised controlled trial. The Lancet 2003, 362:933-940

45. Overgaard J, Mohanti BK, Begum N, et al: Five versus six fractions of radiotherapy per week for squamous-cell carcinoma of the head and neck (IAEA-ACC study): a randomised, multicentre trial. The Lancet Oncology 2010, 11:553-560.

46. Fowler JF, Harari PM, Leborgne F, et al: Acute radiation reactions in oral and pharyngeal mucosa: tolerable levels in altered fractionation schedules. Radiotherapy and Oncology 2003, 69:161-168.

47. Rucci L, Gammarota L, Gallo O: Carcinoma of the anterior commissure of the larynx. II. Proposal of a new staging system. The Annals of Otology Rhinol Laryngol 1996, 105:391-396.

doi:10.1186/1748-717X-6-53

Cite this article as: Tong et al: Impact and relationship of anterior commissure and time-dose factor on the local control of T1N0 glottic cancer treated by 6 MV photons. Radiation Oncology 2011 6:53. 